\title{
Prevalence and correlates of vaccine hesitancy among general practitioners: a cross-sectional telephone survey in France, April to July 2014
}

P Verger $^{1234}$, F Collange ${ }^{125}$, L Fressard ${ }^{123}$, A Bocquier ${ }^{123}$, A Gautier ${ }^{6}$, C Pulcini ${ }^{78}$, J Raude ${ }^{10}$, P Peretti-Watel ${ }^{123}$

1. INSERM, UMR912 'Economics and Social Sciences Applied to Health and Analysis of Medical Information' (SESSTIM), Marseille, France

2. ORS PACA, South-eastern Health Regional Observatory, Marseille, France

3. Aix Marseille Université, UMR_S 912, IRD, Marseille, France

4. INSERM, F-CRIN, Innovative clinical research network in vaccinology (I-REIVAC), GH Cochin Broca Hôtel Dieu, Paris, France

5. Aix Marseille University, URMITE, IRD 198, UMR CNRS 7278, INSERM 1095, Faculté de Médecine, Marseille, France

6. Santé publique France (the French national public health agency), Saint-Maurice, France

7. CHU de Nancy, Service de Maladies Infectieuses et Tropicales, Hôpitaux de Brabois, Vandœuvre-lès-Nancy, France

8. Lorraine University, Paris Descartes University, EA 4360 Apemac, Vandœuvre-lès-Nancy, France

9. EHESP, Sorbonne Paris Cité, Rennes, France

10. Aix-Marseille University, IRD French Institute of Research for Development, EHESP, UMR_D 190 'Emergence des Pathologies Virales', Marseille, France

Correspondence: Pierre Verger (pierre.verger@inserm.fr)

Verger P, Collange F, Fressard L, Bocquier A, Gautier A, Pulcini C, Raude J, Peretti-Watel P. Prevalence and correlates of vaccine hesitancy among general practitioners: a cross-sectional telephone survey in France, April to July 2014. Euro Surveill. 2016;21(47):pii=30406. DOI: http://dx.doi.org/10.2807/1560-7917.

ES.2016.21.47.30406

This article sought to estimate the prevalence of vaccine hesitancy $(\mathrm{VH})$ among French general practitioners (GPs) and to study its demographic, professional and personal correlates. We conducted a cross-sectional telephone survey about GPs' vaccination-related attitudes and practices in 2014 in a national panel of $1,712 \mathrm{GPs}$ in private practice, randomly selected from an exhaustive database of health professionals in France. A cluster analysis of various dimensions of $\mathrm{VH}$ (self-reported vaccine recommendations, perceptions of vaccine risks and usefulness) identified three clusters: $86 \%$ of GPs ( $95 \%$ confidence interval (CI): $84-88$ ) were not or only slightly vaccine-hesitant, $11 \%(95 \%$ $\mathrm{Cl}$ : 9-12) moderately hesitant and $3 \%(95 \% \mathrm{Cl}: 3-4)$ highly hesitant or opposed to vaccination. GPs in the latter two clusters were less frequently vaccinated and reported occasional practice of alternative medicine more often than those in the first cluster; they also described less experience with vaccine-preventable diseases and more experience with patients who they considered had serious adverse effects from vaccination. This study confirms the presence of $\mathrm{VH}$ among French GPs but also suggests that its prevalence is moderate. Given GPs' central role in vaccination, these results nevertheless call for a mobilisation of stakeholders to address VH among GPs.

\section{Introduction}

Vaccine hesitancy (VH) among lay people is defined as delay in acceptance of vaccination, or refusal of vaccination despite the availability of vaccine services, or even acceptance of vaccination with doubts about its safety and benefits; these behaviours and attitudes vary according to vaccine, personal profile and context (SAGE Group) [1]. VH is also frequently denoted as 'a continuum between those that accept all vaccines with no doubts, to complete refusal with no doubts, with vaccine hesitant individuals the heterogeneous group between these two extremes' [2]. VH presents a challenge to physicians, especially to general practitioners (GPs) who are the cornerstone of vaccination implementation in many countries and whose recommendations play an influential role in their patients' vaccination behaviour [3-5]. In France, GPs write prescriptions for $90 \%$ of the vaccinations purchased. Patients may return to the GP for injection after purchasing the vaccine, but they may also see a nurse, make other arrangements or fail to follow up [6].

Although the concept of $\mathrm{VH}$ was initially proposed to describe and qualify lack of acceptance of vaccines by lay people, previous publications showed that also physicians report doubts about risks and usefulness of vaccines [7-9] or low vaccine acceptance for themselves [10-12]. Physicians with such doubts may hesitate to recommend vaccination to their patients. We have previously shown that the frequency of French GPs' self-reported vaccine recommendations for six specific vaccines and target populations (vaccine situations) varied significantly between vaccine situations 


\section{TABLE 1A}

Characteristics of the study population, nationwide panel of general practitioners, weighted data, France, April to July 2014 $(\mathrm{n}=1,582)$

Stratification variables

Sex

Male

Female

1,076

68.0

Age in years (tertiles)

$<50$

$50-58$

$>58$

506

32.0

Density of general practitioners' municipality of practice (Min-Q 1 / $\left.Q_{1}-Q_{3} / Q_{3}-M a x\right)^{a}$

$<-19.3 \%$ of national average

$-19.3 \%$ to $+17.7 \%$ of national average

$>+17.7 \%$ of national average

\begin{tabular}{l|l}
538 & 34.0
\end{tabular}

\begin{tabular}{l|l}
556 & 35.1 \\
\hline
\end{tabular}

\begin{tabular}{l|l}
\hline 488 & 30.8 \\
\hline
\end{tabular}

2012 workload (Min-Q1 / Q1-Q3 / Q3-Max)

$<3,067$ consultations/visits

3,067-6,028 consultations/visits

$>6,028$ consultations/visits

\begin{tabular}{l|r}
406 & 25.7 \\
\hline
\end{tabular}

797

50.4

379

24.0

Professional characteristics

Practice

Solo

Group

662

920

41.9

Coordinator in a retirement home

No

Yes

Work in a healthcare institution

\begin{tabular}{|c|c|c|}
\hline No & 1,315 & 83.1 \\
\hline Yes & 267 & 16.9 \\
\hline \multicolumn{3}{|c|}{ Occasional practice of alternative medicine $\mathrm{e}^{\mathrm{b}}$} \\
\hline No & 1,391 & 87.9 \\
\hline Yes & 191 & 12.1 \\
\hline \multicolumn{3}{|c|}{ Continuing medical education on infectious diseases and vaccination in 2013} \\
\hline No & 899 & 56.8 \\
\hline Yes & 683 & 43.2 \\
\hline \multicolumn{3}{|c|}{ Practice population characteristics } \\
\hline \multicolumn{3}{|c|}{ Proportion of patients younger than 16 years (percentage distribution: quartiles) ${ }^{c}$} \\
\hline $0-16$ & 368 & 25.7 \\
\hline $17-21$ & 356 & 24.8 \\
\hline $22-25$ & 368 & 25.6 \\
\hline $26-50$ & 342 & 23.9 \\
\hline \multicolumn{3}{|c|}{ Experience related to vaccination } \\
\hline \multicolumn{3}{|c|}{ Has had any patients with at least one vaccine-preventable disease in the past 5 years ${ }^{d}$} \\
\hline No & 169 & 10.7 \\
\hline Yes & 1,413 & 89.3 \\
\hline \multicolumn{3}{|c|}{ Has had any patients with a serious health problem potentially related to vaccination } \\
\hline No & 1,328 & 83.9 \\
\hline Yes & 254 & 16.1 \\
\hline
\end{tabular}

a Density of general practitioners' municipality of practice and 2012 workload were categorised so that $25 \%$ of GPs were in the first category, $50 \%$ were in the second and $25 \%$ were in the third category.

${ }^{b}$ Homoeopathy and/or acupuncture.

c 148 missing values.

${ }^{d}$ Five vaccine-preventable diseases were mentioned in the questionnaire: measles, acute or recently diagnosed chronic hepatitis B, bacterial meningitis, cervical cancer and complicated seasonal influenza requiring hospitalisation. 
Characteristics of the study population, nationwide panel of general practitioners, weighted data, France, April to July 2014 $(\mathrm{n}=1,582)$

\begin{tabular}{|c|c|c|}
\hline & Number & $\%$ \\
\hline \multicolumn{3}{|c|}{ Opinions on vaccination in general } \\
\hline \multicolumn{3}{|c|}{ Favourable to vaccination in general } \\
\hline Very favourable & 1,268 & 80.2 \\
\hline Somewhat favourable & 271 & 17.1 \\
\hline Not favourable & 43 & 2.7 \\
\hline \multicolumn{3}{|c|}{ Perceived role towards patients: convince them to vaccinate, even when they are reluctant } \\
\hline No & 163 & 10.3 \\
\hline Yes & 1,419 & 89.7 \\
\hline \multicolumn{3}{|l|}{ Personal vaccinations } \\
\hline \multicolumn{3}{|c|}{ Vaccination against $2013 / 14$ seasonal influenza } \\
\hline No & 449 & 28.4 \\
\hline Yes & 1,133 & 71.6 \\
\hline \multicolumn{3}{|c|}{ Last diphtheria-tetanus-polio (dTPolio) booster } \\
\hline$<10$ years ago & 1,325 & 83.7 \\
\hline $10-20$ years ago & 205 & 13.0 \\
\hline$>20$ years ago & 52 & $3 \cdot 3$ \\
\hline \multicolumn{3}{|c|}{ Vaccination against hepatitis B } \\
\hline Yes, 3 or more doses & 1,364 & 86.2 \\
\hline Yes, fewer than 3 doses & 67 & 4.2 \\
\hline No, or don't remember & 151 & 9.6 \\
\hline
\end{tabular}

and GPs [13]. However, because VH is multidimensional (vaccine recommendation behaviour, perceptions of vaccine risks and usefulness) [14], this finding did not allow us to estimate its prevalence directly. Quantifying VH among physicians is essential if public health measures are to be proposed and appropriately scaled to deal with this problem.

This article has two main objectives: (i) to propose a method that can describe and estimate the extent to which GPs hesitate to recommend vaccines to their patients (VH prevalence), taking into account the multidimensional nature of $\mathrm{VH}$, and (ii) to study the demographic, professional and personal correlates of this $\mathrm{VH}$ and thus determine whether easily measurable GP characteristics can predict the extent of their $\mathrm{VH}$.

\section{Methods}

\section{Population}

We conducted a cross-sectional telephone survey about vaccination in a national panel of 1,712 GPs in private practice in France. The panel was designed to regularly collect data about GPs' medical practices and working conditions; the methods used to set it up have been detailed elsewhere $[13,15]$. In brief, between December 2013 and March 2014, we selected GPs by random sampling from the Ministry of Health's exhaustive database of health professionals in France. GPs planning to retire within 6 months or who practiced exclusively acupuncture or homoeopathy or other alternative medicine were excluded. Sampling was stratified for sex, age, workload (annual number of office consultations and house calls) in 2012 and the density of each GP's municipality of practice. The sample size was set so that the smallest stratum contained at least 10 GPs. The panel's participation acceptance rate was $46 \%$ (1,712 of 3,724 eligible GPs that were contacted). The National Authority for Statistical Information (Commission Nationale de l'Information Statistique) approved the panel.

\section{Procedure and questionnaire}

Professional investigators contacted the members of the panel between April and July 2014 to ask them to participate in the survey. They interviewed those who agreed, using computer-assisted telephone interview software and a standardised questionnaire (questionnaire available from the authors on request) [13]. We had developed the questionnaire after reviewing the literature, conducting qualitative interviews with 10 GPs and discussing the questions with a multidisciplinary panel of experts. We had pilot-tested it for clarity, length and face validity among 50 GPs.

Participants were asked about the frequency at which they recommended vaccines in six specific vaccine situations that we had chosen because current coverage does not meet official French objectives. Participants were also asked about their opinions on the likelihood of associations between purported severe adverse effects and certain vaccines or vaccine adjuvants that 
Typology of general practitioners according to their practices and opinions about vaccination, agglomerative hierarchical cluster analysis, weighted data, France, April to July $2014(\mathrm{n}=1,575)$

\begin{tabular}{|c|c|c|c|c|}
\hline & \multicolumn{3}{|c|}{ Vaccine hesitancy (\%) } & \multirow[b]{2}{*}{ All } \\
\hline & $\begin{array}{c}\text { No-to-slight } \\
n=1,353(85.9 \%)\end{array}$ & $\begin{array}{c}\text { Moderate } \\
\mathrm{n}=166(10.6 \%)\end{array}$ & $\begin{array}{c}\text { High } \\
\mathrm{n}=56(3.5 \%)\end{array}$ & \\
\hline \multicolumn{5}{|c|}{ Perceived likelihood of links between specific vaccines and potential severe adverse effects (somewhat/very likely) } \\
\hline Seasonal influenza vaccine and Guillain-Barré syndrome & 20.1 & 29.9 & 66.2 & 22.8 \\
\hline Hepatitis B vaccine and multiple sclerosis & 5.8 & 30.3 & 82.8 & 11.1 \\
\hline Aluminium adjuvants and Alzheimer's disease & 5.8 & 15.2 & 70.9 & 9.1 \\
\hline $\begin{array}{l}\text { ASo3-adjuvanted influenza } \mathrm{A}\left(\mathrm{H}_{1} \mathrm{~N}_{1}\right) \text { pdmog vaccine Pandemrix } \\
\text { and narcolepsy }\end{array}$ & 13.9 & 28.8 & 46.4 & 16.6 \\
\hline Human papilloma virus vaccine and multiple sclerosis & 0.2 & 27.4 & 50.5 & 4.8 \\
\hline Vaccines containing adjuvant and long-term complications & 24.3 & 48.2 & 88.5 & 29.1 \\
\hline \multicolumn{5}{|l|}{ Perceptions of vaccine usefulness (somewhat/strongly agrees) } \\
\hline $\begin{array}{l}\text { Today some vaccines recommended by authorities are not } \\
\text { useful }\end{array}$ & 23.1 & 40.1 & 60.4 & 26.3 \\
\hline Children are vaccinated against too many diseases & 16.4 & 36.5 & 62.4 & 20.1 \\
\hline \multicolumn{5}{|l|}{ Frequency of vaccine recommendations (often/always) } \\
\hline $\begin{array}{l}\text { Measles-mumps-rubella (MMR) to non-immune adolescents } \\
\text { and young adults }\end{array}$ & 87.1 & 55.8 & 52.6 & 82.6 \\
\hline Meningococcal meningitis C to 12 -month-old infants & 70.9 & 52.8 & 30.6 & 67.6 \\
\hline Meningococcal meningitis C to ages 2-24 years (catch-up) & 60.6 & 36.2 & 20.8 & 56.6 \\
\hline Human papillomavirus vaccine to girls aged $11-14$ years & 77.5 & 46.9 & 24.5 & 72.4 \\
\hline Hepatitis B to adolescents (catch-up) & 67.1 & 41.5 & 29.7 & 63.1 \\
\hline Seasonal influenza to adults under 65 years with diabetes & 87.1 & 69.9 & 47.5 & 83.9 \\
\hline
\end{tabular}

a Seven missing values.

have been or still are the subject of public or scientific debate in France or elsewhere; they were also asked whether they believed vaccines were useful.

Finally, participants were asked about their professional characteristics, own vaccinations, general opinion about vaccination, perception of their role towards patients in this field, experience of severe side effects potentially related to vaccination (leading to hospital admission) and whether any of their patients in the past five years had had any of the following vaccine-preventable diseases (VPDs): measles, acute or recently diagnosed chronic hepatitis $B$ (HBV), bacterial meningitis, cervical cancer or complicated seasonal influenza requiring hospitalisation. Answers were collected with five-point Likert scales that included a 'no opinion' answer for all of these items.

\section{Statistical analysis}

Data were weighted to match the sample more closely to the French national population for stratification variables (sex, age, density of GP's municipality of practice and workload), taking into account the sampling strategy [13] using SURVEY procedures (PROC SURVEYFREQ, PROC SURVEYLOGISTIC, SAS 9.4 statistical software).

A classification of vaccine-related attitudes and behaviours was developed to estimate $\mathrm{VH}$ prevalence among GPs (objective 1) relying on current definitions of $\mathrm{VH}$ that make clear that a person's behaviours and attitudes may vary according to vaccine $[2,7]$. For that purpose, we performed a multiple correspondence analysis (MCA) combined with an agglomerative hierarchical cluster analysis (AHCA) of the different dimensions of GPs' VH [16]. MCA is an exploratory technique used to understand the inter-relationships between multiple categorical variables [17]; it allows correlated variables to be combined into continuous factors [18]. These factors are introduced in the AHCA, which classifies individuals with similar characteristics into clusters. We used a method based on minimum inertia lost to identify the optimal number of clusters $[18,19]$; this was defined as a situation when the total withincluster variance is minimal (individuals with maximum similarity in each cluster) and the between-cluster variance maximal. As $\mathrm{VH}$ is also denoted as a continuum between complete refusal of vaccination (radical rejection) and acceptance of vaccines with certainty (ardent support) [2], we also quantified the prevalence of these two extremes among GPs. In this supplementary approach, we defined 'radical opposition' by the following criteria: rarely or never recommended vaccines in any of the vaccine situations considered in this study AND reported doubts about usefulness AND risks of vaccines. We defined as 'ardent supporters' those GPs who often or always recommended vaccines in all the vaccine situations considered AND did not doubt either usefulness or safety of vaccines. 
General attitudes towards vaccination among the three clusters of general practitioners, weighted data, France, April to July $2014\left(\mathrm{n}=1,575^{\mathrm{a}}\right)$

\begin{tabular}{|c|c|c|c|c|c|}
\hline & \multicolumn{3}{|c|}{ Vaccine hesitancy } & \multirow[b]{2}{*}{ All } & \multirow[b]{2}{*}{$p$ value $^{b}$} \\
\hline & $\begin{array}{c}\text { No-to-slight } \\
n=1,353(85.9 \%)\end{array}$ & $\begin{array}{c}\text { Moderate } \\
\mathrm{n}=166(10.6 \%)\end{array}$ & $\begin{array}{c}\text { High } \\
\mathrm{n}=56(3.5 \%)\end{array}$ & & \\
\hline \multicolumn{6}{|c|}{ Attitudes towards vaccination in general } \\
\hline \multicolumn{6}{|c|}{ Favourable to vaccination in general } \\
\hline Very favourable & 84.7 & 56.2 & 43.4 & 80.3 & \multirow{3}{*}{$<0.0001$} \\
\hline Quite favourable & 14.5 & 35.0 & 24.8 & 17.0 & \\
\hline Not favourable & 0.8 & 8.9 & 31.8 & 2.7 & \\
\hline \multicolumn{6}{|c|}{ Perceived role towards patients: convince them to vaccinate, even when they are reluctant } \\
\hline No & 6.5 & 27.3 & 52.8 & 10.3 & \multirow{2}{*}{$<0.0001$} \\
\hline Yes & 93.5 & 72.7 & 47.2 & 89.7 & \\
\hline \multicolumn{6}{|c|}{ Attitude towards vaccination } \\
\hline Ardent supporter ${ }^{c}$ & 20.6 & 7.4 & 0.0 & 18.5 & \multirow{3}{*}{$<0.0001$} \\
\hline Radical opponent $^{d}$ & 0.0 & 1.3 & 19.0 & 0.8 & \\
\hline Other & 79.4 & 91.3 & 81.0 & 80.7 & \\
\hline
\end{tabular}

a Seven missing values.

${ }^{b}$ Rao-Scott chi-squared test.

' Frequent recommendations (often/always) in all of the six vaccine situations AND no doubts about vaccine usefulness or safety, excluding items regarding the links between Guillain-Barré syndrome and seasonal influenza and between narcolepsy and Pandemrix, which are evidence-based.

${ }^{d}$ Rare recommendations (sometimes/never) in all of the six vaccine situations AND doubts about vaccine usefulness and risks, excluding items regarding the links between Guillain-Barré syndrome and seasonal influenza and between narcolepsy and Pandemrix.

We used the VH classification as a dependent variable. As we found more than two clusters, we tested their potential correlates (objective 2) with univariable and then multivariable ordered logistic regression models adjusted for stratification variables.

We tested the proportional odds assumption with the score test [20] and computed the variance inflation factor (VIF) to test for multicollinearity between explicative variables [21]. To test whether the differences between panel participants and non-participants might have biased the estimations of the regression analyses, we implemented a bivariate probit model with sample selection. This is a system of two simultaneous equations that make it possible to test for the presence of selection bias and to correct it $[22,23]$. The first equation was applied to the whole sample of GPS who could be contacted and were eligible $(n=3,724)$ and analysed the factors associated with participation in the survey using the four stratification variables. The second equation was applied only to GPs who participated in the panel $(n=1,582)$ and studied the factors associated with the $\mathrm{VH}$ classification. Such a model makes it possible to test (and take into account) the correlation (rho) between the error terms that may occur if there are unobservable or unmeasured factors associated with both participation in the survey and vaccine hesitancy, which would bias the estimations; if rho is significant, it is taken into account to calculate unbiased estimates. The likelihood-ratio (LR) test was used to test the null hypothesis of no correlation (rho) between the residuals of these equations.
Finally, we conducted a sensitivity analysis excluding ardent supporters and radical opponents from the multivariable regression. Missing values were excluded from the regression analyses given their limited number.

All analyses were performed in 2015 and based on twosided $p$ values, with statistical significance defined by $p \leq 0.05$; they were conducted with SAS 9.4 statistical software (SAS Institute, Cary, NC).

\section{Results}

In all, 1,712 of 3,724 eligible GPs (46.0\%) agreed to participate in the panel. GPs who refused were more often men $(p \leq 10-3)$, older $(p \leq 10-3)$ and had more consultations in 2012 ( $p \leq 0.05$, data not shown). Two main reasons were reported for refusing: lack of time (55\%) and lack of interest in participating in a panel (31\%). Of the 1,712 GPs included in the panel, 1,582 (92.4\%) participated in the cross-sectional survey; their characteristics did not differ significantly from those of GPS who joined the panel but did not participate in the vaccination survey.

The characteristics of the sample are presented in Table 1 . Among the participants, $80 \%$ were very and $17 \%$ somewhat favourable to vaccination in general, and $90 \%$ reported that they would encourage their patients, even those who are reluctant, to be vaccinated. Some $72 \%$ reported having had a seasonal influenza shot during winter $2013 / 14,84 \%$ had had a diphtheria-tetanus-polio (dTPolio) booster in the past 


\section{TABLE 4}

Factors associated with higher vaccine hesitancy among general practitioners', ordered logistic regressions, weighted data, France, April to July $2014\left(\mathrm{n}=1,427^{\mathrm{a}}\right)$

\begin{tabular}{|c|c|c|}
\hline & Univariable regression & Multivariable regression \\
\hline & $\begin{array}{l}\text { Odds ratio } \\
(95 \% \mathrm{Cl})\end{array}$ & $\begin{array}{l}\text { Adjusted odds ratio } \\
(95 \% \mathrm{Cl})\end{array}$ \\
\hline \multicolumn{3}{|l|}{ Stratification variables } \\
\hline \multicolumn{3}{|l|}{ Sex (ref. Male) } \\
\hline Female & $0.92(0.69-1.23)$ & $0.94(0.63-1.38)$ \\
\hline \multicolumn{3}{|l|}{ Age in years (ref. <50) } \\
\hline $50-58$ & $1.12(0.79-1.59)$ & $0.67(0.44-1.03)$ \\
\hline$>58$ & $1.69(1.19-2.38)$ & $1.00(0.63-1.61)$ \\
\hline \multicolumn{3}{|l|}{ Density of GP's municipality of practice (ref. $\iota-19.3 \%$ of national average) } \\
\hline Between $-19.3 \%$ and $+17.7 \%$ of national average & $0.77(0.55-1.07)$ & $0.76(0.52-1.11)$ \\
\hline$>+17.7 \%$ of national average & $1.09(0.76-1.58)$ & $1.09(0.72-1.66)$ \\
\hline \multicolumn{3}{|l|}{2012 workload (ref. $\ll 3,067$ consultations/visits) } \\
\hline $3,067-6,028$ consultations/visits & $0.39(0.28-0.55)$ & $0.69(0.46-1.04)$ \\
\hline$>6,028$ consultations/visits & $0.50(0.35-0.72)$ & $0.91(0.58-1.45)$ \\
\hline \multicolumn{3}{|l|}{ Professional characteristics } \\
\hline \multicolumn{3}{|l|}{ Practice (ref. Solo) } \\
\hline Group & $0.59(0.45-0.79)$ & $1.10(0.77-1.57)$ \\
\hline \multicolumn{3}{|l|}{ Coordinator in a retirement home (ref. No) } \\
\hline Yes & $0.67(0.35-1.28)$ & $0.92(0.45-1.89)$ \\
\hline \multicolumn{3}{|l|}{ Work in a healthcare institution (ref. No) } \\
\hline Yes & $0.67(0.44-1.02)$ & $0.74(0.45-1.21)$ \\
\hline \multicolumn{3}{|l|}{ Occasional practice of alternative medicine ${ }^{\mathrm{b}}$ (ref. No) } \\
\hline Yes & $5.68(4.04-7.98)$ & $2.89(1.94-4.31)$ \\
\hline \multicolumn{3}{|c|}{ Continuing medical education on infectious diseases and vaccination in 2013 (ref. No) } \\
\hline Yes & $0.65(0.49-0.88)$ & $0.94(0.67-1.32)$ \\
\hline \multicolumn{3}{|l|}{ Characteristics of practice population } \\
\hline Proportion of patients aged under $16(0-50 \%)$ & $0.97(0.95-0.99)$ & $0.99(0.96-1.01)$ \\
\hline \multicolumn{3}{|l|}{ Experience related to vaccination } \\
\hline $\begin{array}{l}\text { Number of different vaccine-preventable diseases among the GP's } \\
\text { patients }(0-5)^{c}\end{array}$ & $0.70(0.62-0.80)$ & $0.78(0.67-0.90)$ \\
\hline \multicolumn{3}{|c|}{ Has had patients with a serious health problem potentially related to vaccination (ref. No) } \\
\hline Yes & $2.30(1.64-3.22)$ & $1.82(1.23-2.68)$ \\
\hline \multicolumn{3}{|l|}{ Personal vaccinations } \\
\hline \multicolumn{3}{|l|}{ Vaccination against 2013-2014 seasonal influenza (ref. Yes) } \\
\hline No & $4.48(3.34-6.01)$ & $2.51(1.78-3.54)$ \\
\hline \multicolumn{3}{|l|}{ Last diphtheria-tetanus-polio (dTPolio) booster (ref. «10 years ago) } \\
\hline $10-20$ years ago & $2.37(1.63-3.43)$ & $1.58(1.02-2.46)$ \\
\hline 220 years ago & $6.60(3.60-12.08)$ & $2.23(1.16-4.26)$ \\
\hline \multicolumn{3}{|l|}{ Vaccination against hepatitis B (ref. Yes, 3 or more doses) } \\
\hline Yes, fewer than 3 doses & $2.76(1.55-4.89)$ & $1.36(0.72-2.57)$ \\
\hline No, or don't remember & $4.22(2.87-6.21)$ & $1.55(0.94-2.55)$ \\
\hline \multicolumn{2}{|l|}{ Nagelkerke $R^{2}$} & 0.21 \\
\hline
\end{tabular}

$\mathrm{CI}$ : confidence interval; GP: general practitioner.

${ }^{a} 155$ GPSs were excluded because of missing values about the characteristics of their practice population $(n=148)$ or about their vaccine hesitancy $(n=7)$.

${ }^{\mathrm{b}}$ Homoeopathy and/or acupuncture.

' Five vaccine-preventable diseases were mentioned in the questionnaire: measles, acute or recently diagnosed chronic hepatitis B, bacterial meningitis, cervical cancer and complicated seasonal influenza requiring hospitalisation. 
10 years and $86 \%$ reported having had three or more doses of vaccine against hepatitis $B$.

Three clusters were identified according to the GPs' vaccination-related behaviours and perceptions (Table 2). The first cluster (no-to-slight hesitancy) included $86 \%$ of GPs (95\% confidence interval $(\mathrm{Cl})$ : $84-88$ ), most of whom considered that vaccines were not at all or not very likely to have severe adverse effects, had no doubts about the usefulness of vaccination and reported recommending vaccination more frequently than the average. The second cluster (moderate hesitancy) included $11 \%$ of GPs (95\% Cl: 9-12): they doubted the safety and usefulness of vaccines more frequently than the average and recommended vaccination less frequently than the sample as a whole. The third cluster (high hesitancy or opposition) included $3 \%$ of GPs ( $95 \% \mathrm{Cl}: 3-4 \%$ ), most of whom considered links between vaccines and severe adverse effects likely or very likely, had doubts about vaccine usefulness, and recommended vaccines much less often than the average.

Overall, $85 \%$ of GPs in cluster $1,56 \%$ in cluster 2 , and $43 \%$ in cluster $3(p<0.0001)$ described themselves as very favourable to vaccination in general. Respectively $94 \%, 73 \%$ and $47 \%(p<0.0001)$ agreed that their role is to encourage their patients to be vaccinated, even when patients are reluctant (Table 3 ).

In the supplementary continuum approach, $18.5 \%$ of GPs were ardent supporters of vaccination (21\% in cluster $1,7 \%$ in cluster 2 and $0 \%$ in cluster 3 ), while the proportion of radical opponents was $0.8 \%$ (0\% in cluster 1, 1\% in cluster 2 and 19\% in cluster 3; Table 3). Excluding the ardent supporters and radical opponents from the analysis, in accordance with the standard definition of $\mathrm{VH}$, yielded an estimated prevalence of moderate-to-high $\mathrm{VH}$ among GPs of $13 \%$ (95\% Cl: $11-14)$ instead of $14 \%$ ( $95 \% \mathrm{Cl}: 12-16)$ without this exclusion.

The proportional-odds hypothesis was not rejected in the final specified model of the multivariable ordered logistic regression (chi-square $(20)=26.4 ; p=0.15$ ). GPs who practiced alternative medicine occasionally, those with no patients who had had one of the five included VPDs, those who had had patients with a serious health problem leading to hospitalisation that might have been related to vaccination as well as those who did not adhere to seasonal influenza or dTPolio vaccine recommendations for themselves, were more prone to moderate-to-high $\mathrm{VH}$ in univariable as well as multivariable regressions adjusted for the four stratification variables (Table 4 ). The test for multicollinearity was negative $(\mathrm{VIF}<5)$. The $L R$ test for the bivariate probit model with sample selection indicated that the estimations of the multivariable regression analysis were unbiased ( $r h o=0.77 ; p=0.42$ ). Exclusion of vaccination supporters and opponents from the analysis produced similar estimates of the odds ratios for the variables of interest (data not shown; results available from the authors on request).

\section{Discussion}

The prevalence of moderate-to-high $\mathrm{VH}$ was $14 \%$. Compared with those with no-to-slight VH, GPs with moderate-to-high $\mathrm{VH}$ were less frequently vaccinated, reported more often that they occasionally practiced alternative medicine, and reported fewer patients with VPDs and more with serious adverse effects possibly due to vaccination.

Despite the moderate prevalence of $\mathrm{VH}$ among GPs, our results are worrying because GPs play an essential role in vaccinating their patients, answering their questions and addressing their VH (a growing phenomenon in the general population [24]). Evidence indicates that most parents seek information and advice from their healthcare provider regarding VPDs, vaccines and the recommended vaccination schedule [25]. GPs with moderate-to-high $\mathrm{VH}$ were less prone to try to convince hesitant patients to be vaccinated (or have their children vaccinated). A previous publication showed a strong positive association between the frequency of GPs' recommendations for various vaccines and their self-perceived efficacy in explaining the benefits and risks of vaccines to their patients [13]. Given the strong influence of GPS on their patients' vaccination decisions [3-5], their $\mathrm{VH}$ may impede efforts to alleviate patients' VH.

The strong association between occasional practice of alternative medicine and moderate-to-high $\mathrm{VH}$ was expected: physicians belonging to this category were those who occasionally practiced homoeopathy or acupuncture; they accounted for $12 \%$ of GPs [26] in France in 2010. These GPs vaccinate themselves less frequently than other GPs (e.g. against hepatitis B and pandemic and seasonal influenza [27]) and are frequently less favourable to vaccination than other physicians [13]. Previous studies showed reduced adherence to paediatric vaccination schedules and reduced acceptance of vaccines in their patients [28].

Our results suggest that GPs' experience of both VPD and adverse effects of vaccines may influence their $\mathrm{VH}$ level more than their academic education in infectious diseases and vaccination. GPs with moderate-tohigh hesitancy may perceive that adverse effects are more common than those with no-to-slight hesitancy. Our results are also consistent with previous publications that found that GPs' knowledge from their own individual practice experience and from the Internet, the media and patients might be more influential than academic and technical knowledge in shaping GPs' perceptions of the risk/benefit balance of vaccines, especially in controversial situations [29]. This could be explained in part by the major gaps identified in Europe, including France, in the initial training and continuous medical education of physicians regarding vaccination, by the difficulties in keeping them informed 
during continuously evolving situations and, in some cases, by feelings of distrust towards health institutions $[13,30]$.

Surprisingly, doubts existed about vaccine risks even among the numerous GPs with no-or-slight $\mathrm{VH}$. This remained true even after excluding answers about the two evidence-based risks: Guillain-Barré syndrome after seasonal influenza vaccination and narcolepsy after Pandemrix vaccination [31]. The safety of vaccines and adjuvants has been the subject of persistent controversy in France since the 1990s. While French GPs do not consider the media to be a reliable source of information in the field of vaccination [13], the media's role in setting the risk agenda and its amplification of controversial positions may affect perceptions of vaccine risks in GPs as much as it does in the lay population. Observing these doubts among the least hesitant GPs, most of whom were very favourable to vaccination in general, shows how fragile their pro-vaccination attitudes may be.

The fact that a quarter of the least hesitant GPs thought that some vaccines recommended by French health authorities are not useful is also surprising. Doubts among physicians about the usefulness of vaccines have been observed in studies throughout the world [7]; some doctors consider that certain VPDs are too infrequent to justify systematic vaccination, a perception shared by some French GPs, in particular for meningitis C and hepatitis B [32]. These perceptions may also reflect the opinion that the official French vaccine schedule is becoming increasingly complex: constant change to the schedule makes it difficult for doctors to adapt and may adversely affect patient acceptance [32].

\section{Limitations}

By joining the panel, GPs agreed to take part in five different surveys during a 30-month period: the good participation rate $(46 \%)$ compared with other primary physician panels (for example the panel in Joyce et al. (2010) with a response rate of $19.4 \%$ [33]), does not rule out the possibility of selection bias. In particular, panel participants and non-participants differed in age, sex and workload [13]. Nonetheless, we weighted the sample according to these variables, which should have corrected a potential selection bias. Moreover, to limit potential selection bias related to particular attitudes about vaccination, the specific topic of the surveys was not mentioned to GPs when they were first invited to participate in the panel. In the overall panel, participants in the vaccination survey did not differ from nonparticipants. Finally, the results of the bivariate probit model indicated that the regression parameters of the multivariable model were unbiased.

GPs' vaccine recommendation behaviour was selfreported, which is a limitation that our study shares with previous publications: declaration or desirability biases cannot be excluded. However, questionnaire data appears to overestimate vaccination rates by less than $10 \%$ [34] and self-reported vaccination coverage (e.g. for pandemic or seasonal influenza) in hospital healthcare workers has been shown to be a good proxy for recorded vaccine coverage [35]. In any case, our study's aim was not to estimate vaccine coverage among GPs but the prevalence of VH among them. GPs' self-reported recommendations are useful indicators for that purpose because (i) they reflect in part the degree to which GPs are favourable to vaccines and (ii) retrieving reliable information about GPs' recommendation behaviour from patients' files was not feasible [13]. In addition, this questionnaire method is easily reproducible and could be used to monitor trends in VH over time for GPs.

Because this vaccination survey was cross-sectional and retrospective, no causal inferences can be drawn. Finally, we may not be able to extrapolate our results directly to other countries where $\mathrm{VH}$ is likely to exist among healthcare workers [36] because some of the vaccine situations we addressed in this study are specific mainly to France.

The approach used in this article allowed us to estimate VH prevalence among GPs while taking its multidimensional nature into account. The resulting $\mathrm{VH}$ typology appears robust: it was strongly correlated with the GPs' own vaccination behaviour and with their opinion towards vaccination in general. That approach can be applied elsewhere, although the vaccines and target populations chosen would probably differ from those selected here.

\section{Conclusions}

Our results underline the need to better coordinate the mobilisation efforts by public health institutions and other actors to address VH among GPs in France. Efforts should be directed with priority to GPs with moderate-to-high VH. Nonetheless, efforts to inform and support GPs with no-to-low VH are also warranted to prevent some of the existing reservations and the expansion of $\mathrm{VH}$ in this group.

Improving GPs' knowledge of vaccination and vaccines is a necessary but not sufficient condition to modify their behaviours and attitudes in this area [36]. This should lead health authorities to promote and evaluate multicomponent interventions including in particular education, individualised feedback and strong quality incentives, all of which have proven to be effective strategies [37]. Given the variation of VH intensity between GPs, tailored interventions taking GPs' baseline $\mathrm{VH}$ level into account should be tested. More research is needed to quantify and monitor $\mathrm{VH}$ in different medical occupations and in different countries.

\section{Acknowledgements}

We are grateful to Jo Ann Cahn for revising and clarifying the text. 
The study was funded by the Directorate of Research, Studies, Evaluation and Statistics (DREES) of the Ministry of Social Affairs and Health and the National Institute for Prevention and Education in Health (INPES). This research has also separately received funding from the French National Research Agency (call for proposals issued in 2015) and, as part of the "Primary Prevention" call for proposals issued by the French Institute for Public Health Research (IReSP) and the INCa in 2013, from the French National Health Insurance Fund for Employees (CNAM-TS), the French Directorate General of Health (DGS), the Arc Foundation for Cancer Research, the French National Cancer Institute (INCa), the INPES, the French National Institute of Health and Medical Research (INSERM), the French Interdepartmental Agency for the Fight against Drugs and Addictive Behaviors (Mildeca) and the French Social Security Plan for the Self-Employed (RSI).

\section{Conflict of interest}

None declared.

\section{Authors' contributions}

F. Collange, A. Bocquier, A. Gautier, J. Raude, C. Pulcini and $P$. Peretti-Watel designed the questionnaire and critically revised the manuscript. P. Verger conceived, designed and supervised the study, interpreted the data, and drafted the manuscript. L. Fressard performed the statistical analysis, interpreted the data, and critically revised the manuscript.

\section{References}

1. Larson HI, Jarrett C, Eckersberger E, Smith DMD, Paterson $P$. Understanding vaccine hesitancy around vaccines and vaccination from a global perspective: a systematic review of published literature, 2007-2012.Vaccine. 2014;32(19):2150-9. DOI: 10.1016/j.vaccine.2014.01.081 PMID: 24598724

2. MacDonald NE, SAGE Working Group on Vaccine Hesitancy. Vaccine hesitancy: Definition, scope and determinants.Vaccine. 2015;33(34):4161-4. DOI: 10.1016/j.vaccine.2015.04.036 PMID: 25896383

3. Gust DA, Darling N, Kennedy A, Schwartz B. Parents with doubts about vaccines: which vaccines and reasons why. Pediatrics. 2008;122(4):718-25. DOI: 10.1542/peds.2007-0538 PMID: 18829793

4. Freed GL, Clark SJ, Cowan AE, Coleman MS. Primary care physician perspectives on providing adult vaccines.Vaccine. 2011;29(9):1850-4. DOI: 10.1016/j.vaccine.2010.12.097 PMID: 21216314

5. Schwarzinger M, Verger P, Guerville MA, Aubry C, Rolland $S$, Obadia Y, et al. Positive attitudes of French general practitioners towards $\mathrm{A} / \mathrm{H}_{1} \mathrm{~N}_{1}$ influenza-pandemic vaccination: a missed opportunity to increase vaccination uptakes in the general public? Vaccine. 2010;28(15):2743-8. DOI: 10.1016/j. vaccine.2010.01.027 PMID: 20117271

6. Ecole des Hautes Etudes en Santé Publique (EHESP). Faciliter l'accès aux vaccinations en s'appuyant sur les Agences Régionales de Santé. [Facilitate access to vaccinations with the support of the Regional Health Agencies]. Rennes: EHESP; 2013. French. Available from: http://fulltext.bdsp.ehesp.fr/ Ehesp/Memoires/mip/2013/groupe_8.pdf

7. Dubé E, Laberge C, Guay M, Bramadat P, Roy R, Bettinger J. Vaccine hesitancy: an overview. Hum Vaccin Immunother. 2013;9(8):1763-73. DOI: 10.4161/hv.24657 PMID: 23584253

8. Daley MF, Crane LA, Markowitz LE, Black SR, Beaty BL, Barrow J, et al. Human papillomavirus vaccination practices: a survey of US physicians 18 months after licensure. Pediatrics. 2010;126(3):425-33. DOI: 10.1542/peds.2009-3500 PMID: 20679306

9. Verger P, Flicoteaux R, Schwarzinger M, Sagaon-Teyssier L, Peretti-Watel P, Launay 0 , et al. Pandemic Influenza $\left(A / \mathrm{H}_{1} \mathrm{~N}_{1}\right)$ Vaccine Uptake among French Private General Practitioners: A Cross Sectional Study in 2010. McVernon J, editor. PLoS ONE. 2012;7(8):e41837.

10. Poland GA. The 2009-2010 influenza pandemic: effects on pandemic and seasonal vaccine uptake and lessons learned for seasonal vaccination campaigns.Vaccine. 2010;28(Suppl 4):D313. DOI: $10.1016 / j . v a c c i n e .2010 .08 .024$ PMID: 20713258

11. Bish A, Yardley L, Nicoll A, Michie S. Factors associated with uptake of vaccination against pandemic influenza: a systematic review.Vaccine. 2011;29(38):6472-84. DOI: 10.1016/j. vaccine.2011.06.107 PMID: 21756960

12. Haviari S, Bénet T, Saadatian-Elahi M, André P, Loulergue P, Vanhems P. Vaccination of healthcare workers: A review. Hum Vaccin Immunother. 2015;11(11):2522-37. DOI: 10.1080/21645515.2015.1082014 PMID: 26291642

13. Verger P, Fressard L, Collange F, Gautier A, Jestin C, Launay $O$, et al. Vaccine Hesitancy Among General Practitioners and Its Determinants During Controversies: A National Crosssectional Survey in France. EBioMedicine. 2015;2(8):891-7. DOI: 10.1016/j.ebiom.2015.06.018 PMID: 26425696

14. Peretti-Watel P, Larson HJ, Ward JK, Schulz WS, Verger P. Vaccine hesitancy: clarifying a theoretical framework for an ambiguous notion. PLoS Curr. 2015;7:ecurrents.outbreaks.684 4c8off9f5b273f34c91f71b7fc289.

15. Le Maréchal M, Collange F, Fressard L, Peretti-Watel P, Sebbah $\mathrm{R}$, Mikol F, et al. Design of a national and regional survey among French general practitioners and method of the first wave of survey dedicated to vaccination. Med Mal Infect. 2015;45(10):403-10. DOI: 10.1016/j.medmal.2015.09.005 PMID: 26494319

16. Kaufman L, Rousseeuw PJ. Finding Groups in Data: An Introduction to Cluster Analysis. Hoboken: John Wiley and Sons; 1990.

17. Greenacre M. Correspondence analysis in medical research.Stat Methods Med Res. 1992;1(1):97-117. DOI: 10.1177/096228029200100106 PMID: 1341654

18. Antón-Ladislao A, García-Gutiérrez S, Soldevila N, GonzálezCandelas F, Godoy P, Castilla J, et al. Visualizing knowledge and attitude factors related to influenza vaccination of physicians. Vaccine. 2015;33(7):885-91. DOI: 10.1016/j. vaccine.2014.12.012 PMID: 25529290

19. Ward JH. Hierarchical Grouping to Optimize an Objective Function.J Am Stat Assoc. 1963;58(301):236-44 .DOI: $10.1080 / 01621459.1963 .10500845$

20. Peterson B, Harrell FE. Partial Proportional Odds Models for Ordinal Response Variables.Appl Stat. 1990;39(2):205 .DOI: $10.2307 / 2347760$

21. Rogerson P. Statistical Methods for Geography. London: SAGE; 2011.

22. Heckman J. Sample selection bias as a specification error. Econometrica. 1979;47(1):153-61 .DOI: 10.2307/1912352

23. Greene W. Econometric Analysis. Upper Saddle River, N.J.: Prentice Hall; 2003.

24. Peretti-Watel P, Verger P, Raude J, Constant A, Gautier A, Jestin $C$, et al. Dramatic change in public attitudes towards vaccination during the 2009 influenza $A\left(\mathrm{H}_{1} \mathrm{~N}_{1}\right)$ pandemic in France. Euro Surveill. 2013;18(44):20623. DOI: 10.2807/15607917.ES2013.18.44.20623 PMID: 24176658

25. Wheeler M, Buttenheim AM. Parental vaccine concerns, information source, and choice of alternative immunization schedules. Hum Vaccin Immunother. 2013;9(8):1782-9. DOI: 10.4161/hv.25959 PMID: 23900266

26. Barlet M, Coldefy M, Collin C, Gabrielli VL. L'Accessibilité potentielle localisée (APL): une nouvelle mesure de ['accessibilité aux soins appliquée aux médecins généralistes libéraux en France [Internet]. Paris: IRDES; 2012 [cited 2016 May 30]. Available from: https://ideas.repec.org/p/irh/wpaper/ dt51.html

27. Pulcini C, Massin S, Launay O, Verger P. Factors associated with vaccination for hepatitis $B$, pertussis, seasonal and pandemic influenza among French general practitioners: a 2010 survey.Vaccine. 2013;31(37):3943-9. DOI: 10.1016/j. vaccine.2013.06.039 PMID: 23806242

28. Downey L, Tyree PT, Huebner CE, Lafferty WE. Pediatric vaccination and vaccine-preventable disease acquisition: associations with care by complementary and alternative medicine providers. Matern Child Health J. 2010;14(6):922-30. DOI: 10.1007/S10995-009-0519-5 PMID: 19760163

29. Brownlie J, Howson A. 'Between the demands of truth and government': health practitioners, trust and immunisation work.Soc Sci Med. 2006;62(2):433-43. DOI: 10.1016/j. socscimed.2005.05.033 PMID: 16046042

30. Vorsters A, Tack S, Hendrickx G, Vladimirova N, Bonanni P, Pistol A, et al. A summer school on vaccinology: Responding to identified gaps in pre-service immunisation training of future health care workers. Vaccine. 2010;28(9):2053-9. DOI: 10.1016/j.vaccine.2009.12.033 PMID: 20038430

31. Miller E, Andrews N, Stellitano L, Stowe J, Winstone AM, Shneerson J, et al. Risk of narcolepsy in children and young people receiving $\mathrm{ASO}_{3}$ adjuvanted pandemic $\mathrm{A} / \mathrm{H}_{1} \mathrm{~N}_{1} 2009$ 
influenza vaccine: retrospective analysis. BM). 2013;346(feb26 2):f794-f794.

32. Larson H, Karafillakis E. Vaccine Hesitancy amongst Healthcare Workers and Their Patients in Europe : A Qualitative Study Vaccine Confidence Project. London: London School of Hygiene and Tropical Medicine; 2015.

33. Joyce CM, Scott A, Jeon S-H, Humphreys J, Kalb G, Witt J, et al. The "medicine in Australia: balancing employment and life (MABEL)" longitudinal survey--protocol and baseline data for a prospective cohort study of Australian doctors' workforce participation. BMC Health Serv Res. 2010;10(1):50. DOI: 10.1186/1472-6963-10-50 PMID: 20181288

34. Brien S, Kwong JC, Buckeridge DL. The determinants of 2009 pandemic $\mathrm{A} / \mathrm{H}_{1} \mathrm{~N}_{1}$ influenza vaccination: a systematic review.Vaccine. 2012;30(7):1255-64. DOI: 10.1016/j. vaccine.2011.12.089 PMID: 22214889

35. Llupià A, García-Basteiro AL, Mena G, Ríos J, Puig J, Bayas JM, et al. Vaccination Behaviour Influences Self-Report of Influenza Vaccination Status: A Cross-Sectional Study among Health Care Workers. Caylà JA, editor. PLoS ONE. 2012;7(7):e39496.

36. MacDonald NE, Dubé E. Unpacking Vaccine Hesitancy Among Healthcare Providers. EBioMedicine. 2015;2(8):792-3. DOI: 10.1016/j.ebiom.2015.06.028 PMID: 26425679

37. Perkins RB, Zisblatt L, Legler A, Trucks E, Hanchate A, Gorin SS. Effectiveness of a provider-focused intervention to improve HPV vaccination rates in boys and girls.Vaccine. 2015;33(9):1223-9. DOI: 10.1016/j.vaccine.2014.11.021 PMID: 25448095

\section{License and copyright}

This is an open-access article distributed under the terms of the Creative Commons Attribution (CC BY 4.0) Licence. You may share and adapt the material, but must give appropriate credit to the source, provide a link to the licence, and indicate if changes were made.

This article is copyright of the authors, 2016. 